American Journal of Pharmaceutical Education 2019; 83 (1) Article 6968.

\title{
COMMENTARY
}

\section{Pharmacy Schools Should Be Involved in Disaster Preparedness Planning at the Local and State Levels}

\author{
Gannett Monk, PharmD, BS Pharm, Suyasha Pradhan, PharmD \\ University of Charleston School of Pharmacy, Charleston, West Virginia \\ Submitted January 22, 2018; accepted August 21, 2018; published February 2019.
}

With the occurrence of several recent extreme weather events in the United States, the opportunities are great for schools and colleges of pharmacy to become involved with disaster planning at their local and state levels. The University of Charleston School of Pharmacy (UCSOP) became involved in one such extreme weather event when torrential rains struck residents of West Virginia. On June 23, 2016, multiple areas of central West Virginia experienced one of the deadliest flash floods in recent US history. ${ }^{1}$ The impact to the Clendenin and Elkview communities was especially unusual, as three of the area pharmacies (Riverview Pharmacy, Clendenin Pharmacy, and Rite Aid Pharmacy) were forced to close their doors due to damage from the floodwater. Three other area pharmacies (Kmart Pharmacy, Kroger Pharmacy, and CVS Pharmacy) became completely inaccessible when floodwaters swept away the bridge to the shopping center in which they were located. The floodwaters rose so rapidly that many residents were forced to flee their homes with no personal effects, including their medications. As a result, the patients in the area were left with no medications nor any mechanism with which to obtain their maintenance medications. In addition, many of these patients did not even have a record of what medications they regularly used.

To meet the needs of the affected residents, the local hospital system, Charleston Area Medical Center (CAMC), set up a medical clinic. By the first day of operation, it became evident that there was a huge need for pharmacy services. As many of the residents in the area had no medications or medication lists, pharmacists were needed to determine what medications patients needed to manage their chronic conditions, as well as to manually fill those prescriptions. CAMC's on-site clinic staff had only one pharmacist the first day of the response, and they struggled to meet the needs of the patients. CAMC provided more pharmacists on the second day but realized

Corresponding Author: Gannett Monk, University of Charleston School of Pharmacy, 2300 MacCorkle Ave., S.E. Charleston, WV 25304. Tel: 304-357-4353. E-mail: gannettmonk@ucwv.edu that they could not continue to meet the long-term needs of the large number of patients without further pharmacist intervention. Using social media, the medical director of the clinic sent out an urgent request for any West Virginia licensed pharmacist to volunteer their services to help staff the clinic alongside the CAMC pharmacists. Upon notification, UCSOP responded that it was willing and able to supply multiple pharmacists each day to help staff the tent, and did so until the emergency was resolved. The pharmacists from UCSOP were faculty members either removed from their practice sites, or available due to low teaching demand during the summer break. The tent was staffed by 17 CAMC pharmacists and 11 UCSOP pharmacists for 12 days. Using these 224 pharmacy manhours, 718 prescriptions were dispensed, costing more than $\$ 40,000$. CAMC donated the medications and used its outpatient pharmacy to fill the prescriptions. However, discerning which medications each patient needed proved to be difficult. Working with the patients, the pharmacists discussed the various disease states that each patient had, discerned which medical providers ordered the medications and where the prescriptions had been previously filled. Using these leads, pharmacists reached out to other branches of the patients' pharmacies or provider offices to access their records and managed to patch together medication histories for each patient. The medical director of the clinic authorized the writing of the prescriptions for each patient once the pharmacists verified each medication, and CAMC provided a 14-day supply to last until the medical community could rebound. Throughout the response effort, emergency planners and responders remarked again and again that they would have never thought to ask a pharmacy school for help, not realizing the availability and abilities.

Following the disaster response, UCSOP was invited to attend "after action" meetings involving the local Kanawha-Charleston Health Department and local emergency planners and responders. These meetings allowed all parties involved to reflect on what went right, what went wrong, and what could improve preparedness for future disasters. One thing that was apparent during these 


\section{American Journal of Pharmaceutical Education 2019; 83 (1) Article 6968.}

reflective meetings was that the pharmacy response could have been more effective had UCSOP been involved in the planning and preparation before the disaster occurred. Had the local health department or emergency planners been aware of the possible services that UCSOP faculty, staff and students could provide, those resources would have been involved from day one and could have an even more meaningful impact on the affected residents.

Going forward, the local and state disaster planning agencies are now aware of UCSOP's abilities in times of need - be it immunization, medication dispensing, patient screenings, patient education, drug therapy management, etc. While specific plans are dependent upon the specific disaster, the Kanawha-Charleston Health Department is aware that UCSOP can provide faculty, staff and students to complete a variety of needed pharmaceutical services upon request. By identifying a dedicated faculty member to stay involved in these disaster planning meetings, and including faculty, staff and students in local emergency response training exercises, the expectation is that UCSOP can play an even larger role in any future disasters in the area.

The American Public Health Association encourages these types of broad collaborations to enable pharmacists to assist in public health planning, emergency preparedness and to coordinate the delivery of pharmaceutical supplies during events. ${ }^{2}$ The National Association of County and City Health Officials (NACCHO) also encourages partnerships between local health departments and the pharmacy community, and specifically identifies pharmacy schools as a resource for preparedness planning and response activities, as their knowledge and skills are useful in improving response efforts. ${ }^{3}$ While there are many examples in the literature of pharmacists assisting with disaster relief and exhibiting their value on those teams, examples of pharmacy schools assisting are more scarce. ${ }^{4}$ Hogue and colleagues describe the efforts of the McWhorter School of Pharmacy at Samford University assisting with the disaster response following Hurricane Katrina. By providing care to hurricane evacuees, the McWhorter School of Pharmacy was able to reduce the number of patients with non-emergent problems seeking care in local hospital emergency departments. Hogue and colleagues explained that the response was particularly efficient because the school already had a relationship with the Jefferson County Department of Health, and that the schedules of the practice faculty were more flexible than pharmacists working full-time in a hospital or community pharmacy setting. ${ }^{5}$ The University of MissouriKansas City School of Pharmacy faculty, staff and students participated in the disaster response following the Joplin, Missouri tornado of 2011, helping with everything from first response, cleanup and donation drives to dispensary site set up, medication supply chain and vaccination administration. The school's previously established relationships and flexible schedules of volunteers made the effort more effective and efficient in the time of crisis. ${ }^{6}$ These examples of pharmacy schools participating in disaster relief activities demonstrate more than just aid to a community - they are learning experiences for the students involved, and likely encourage these future pharmacists to be more engaged in disaster preparedness activities in their future practices.

Another issue that arose from the flood event of 2016 in West Virginia was the need to update state pharmacy laws with respect to times of disaster. In the state of West Virginia, there was no process in place by which a pharmacist licensed in another state could perform pharmacist duties during the time of a declared disaster. Many pharmacists paired with national organizations willing to help (such as the Red Cross) were unable to step in and perform the required pharmacist duties, because they were not licensed in the state. In addition, mobile pharmacies were required to undergo a process of individual approval and inspection by the board of pharmacy before beginning dispensing duties. These issues provided an advocacy opportunity for the UCSOP community to work toward having these laws amended, and prepare for a better response during the next disaster. As a result of the disaster and advocacy efforts, the West Virginia Board of Pharmacy is currently in the process of implementing a comprehensive disaster preparedness plan. The proposed disaster preparedness plan includes allowing for pharmacists licensed in other states to provide services in West Virginia during periods of a declared disaster, and allows for mobile pharmacies to more quickly provide services during these periods. In a 2014 survey of 53 boards of pharmacy in the United States and its territories, Lowe found that $39 \%$ of respondents require an out-of-state pharmacist to apply for a temporary license in order to participate in disaster relief efforts, $89 \%$ allow for the establishment of temporary or mobile pharmacies following a disaster, and only $18 \%$ allow for expanded roles for pharmacists in disaster relief efforts. ${ }^{7}$ Pharmacy schools searching for advocacy initiatives are encouraged to research individual state pharmacy laws, and work to update them to allow pharmacists to maximize their contribution to the next disaster relief effort.

In addition to advocacy efforts, there are several other initiatives that pharmacy schools can implement to become more engaged in disaster preparedness planning. A first step is to assign a representative to work with local and state disaster preparation groups to alert them to the services that could be provided in times of need by faculty, staff and students, as encouraged by NACCHO. ${ }^{3}$ A second step is to assess the degree to which pharmacy 


\section{American Journal of Pharmaceutical Education 2019; 83 (1) Article 6968.}

students in your institution are educated about disaster preparedness, and consider adding required or elective course content. An example of this is documented by MacDonald at the University of North Carolina at Chapel Hill, where students and faculty in the departments of public health, pharmacy and medicine participate in integrated learning and service, in collaboration with state and local health departments. ${ }^{8}$ As Lowe concludes, "requiring or simply offering optional disaster relief and public health training to pharmacy students will increase their competence and awareness to handle a state of emergency." A third step is to encourage the involvement of faculty, staff and students in the Medical Reserve Corps, a community-based organization consisting of 190,000 medical and public health professionals and community members with the goal to "improve the health and safety of their communities." 9 Pharmacist members of the Medical Reserve Corps provided care to evacuees from Hurricanes Katrina and Rita using the training and preparation that the local organization provided. ${ }^{10} \mathrm{~A}$ fourth step for pharmacy faculty members interested in disaster preparedness planning is to join the public health special interest group of the American Association of Colleges of Pharmacy, which has a subcommittee on emergency preparedness and response.

\section{CONCLUSION}

The collaboration between Charleston Area Medical Center, the Kanawha-Charleston Health Department and the University of Charleston School of Pharmacy exhibits the capacity for a school of pharmacy to help patients in a time of natural disaster. Pharmacy schools across the country prepare and train their students to serve their communities, emphasizing the integral role pharmacists play in patients' wellness. Participating in disaster relief efforts is an intense, but rewarding opportunity that exemplifies what it means to serve one's community and patients. In an encouraging 2015 survey of 134 pharmacy schools predominantly in the US, Mager and colleagues reported that $71 \%$ of responding schools collaborate with local and/or state public health departments. ${ }^{11}$ While many pharmacy schools may already be at their local disaster preparedness planning tables, references of this in the literature are relatively rare, and this call to action is warranted for the benefit of patients, communities, students, schools and the profession of pharmacy.

\section{REFERENCES}

1. Visser S, Savidge M. West Virginia floods devastate 1,200 homes, many lives. July 1, 2016. http://www.cnn.com/2016/06/28/us/westvirginia-flooding-weather/index.html. Accessed June 1, 2018.

2. Landesman LY. Public Health Management of Disasters: The Practice Guide. $3^{\text {rd }}$ ed. Washington, DC: American Public Health Association; 2012:30-33.

3. Statement of Policy: Pharmacy Partnerships for Emergency Response. National Association of County and City Health Officials. https:/www.naccho.org/uploads/downloadable-resources/14-03Pharmacy-Partnerships-for-Emergency-Response.pdf. Accessed July 23, 2018.

4. Moore AF, Kenworthy L. Disaster relief: a look into the pharmacist's role. NC Med J. 2017;78(3):195-197.

5. Hogue MD, Hogue HB, Lander RD, Avent K, Fleenor M. The nontraditional role of pharmacists after hurricane Katrina: process description and lessons learned. Public Health Rep. 2009;124(2):

217-223.

6. University of Missouri-Kansas City School of Pharmacy. Joplin 2011: From Tragedy to Recovery. https://pharmacy.umkc.edu/wpcontent/uploads/2014/06/Postscript_2010-11.pdf. Accessed July 23, 2018.

7. Lowe RA. Roles and regulations for pharmacists in state-level disaster relief efforts. http://thesis.honors.olemiss.edu/191/1/Roles\% 20 and $\% 20$ Regulations $\% 20$ for $\% 20$ Pharmacists $\% 20$ in $\% 20$ StateLeve1\%20Disaster\%20Relief\%20Efforts.pdf. Accessed July 23, 2018.

8. MacDonald PD. Team epi-aid: graduate student assistance with urgent public health response. Public Health Rep. 2005;

120(Suppl 1):35-41.

9. US Department of Health and Human Services. About the Medical Reserve Corps. https://mrc.hhs.gov/pageViewFldr/About. Accessed July 23, 2018.

10. Young D. Medical Reserve Corps pharmacists assist evacuees. Am J Health Syst Pharm. 2006;63(4):296,299-300,302.

11. Mager NAD, Ochs L, Ranelli PL, et al. Partners in public health: public health collaborations with schools of pharmacy, 2015. Public Heath Rep. 2017;132(3):298-303. 